\title{
DYNAMIC EQUILIBRIUM IN THE HOSPITAL INDUSTRY
}

\author{
GAUTAM GOWRISANKARAN \\ Department of Economics \\ University of Minnesota \\ 271 19th Avenue South \\ Minneapolis, MN 55455 \\ gautam@atlas.socsci.umn.edu \\ ROBERT J. TOWN \\ Graduate School of Management \\ University of California, Irvine \\ Irvine, CA 92697 \\ rjtown@uci.edu
}

We present a dynamic model of the hospital industry in which nonprofit and for-profit hospitals coexist and compete and are differentiated by their objective functions, investment technologies, and taxation rates. In our model, patients differ by income and type of insurance coverage, and choose admission to their preferred hospital, while hospitals choose investment, entry, exit, and pricing strategies. We estimate the parameters of the model with aggregate data and a GMM procedure. We then use the model to examine the effects of changes in the Medicare reimbursement system, universal health-care coverage, and taxation of nonprofits.

\section{INTRODUCTION}

The recent history of the US hospital industry has been marked by turbulent regulatory and institutional changes. Just within the last decade the industry has seen dramatic declines in Medicare reimbursement

We have received helpful comments from Dan Ackerberg, Steve Berry, Randy Ellis, Chaim Fershtman, Tom Holmes, Ariel Pakes, Greg Vistnes, and anonymous referees. Gowrisankaran received financial support from the Social Sciences and Humanities Research Council of Canada (Doctoral Fellowship 752-93-0054), the Alfred P. Sloan Foundation (Doctoral Dissertation Fellowship), and Yale University. Portions of this work were completed while Town was a visiting fellow at ISPS at Yale University. This paper is a revised version of the paper presented at the Second Industrial Organization of Health Care Conference. 
rates, the rise of managed care, deregulation of hospital investment and pricing decisions, and technological advances in drug treatments and outpatient surgery. These changes have had or likely will have immense, sustained, and dynamic effects upon both the demand for and the supply of hospital services. As the hospital sector is responsible for some 5\% of US GDP, it has long been recognized that the task of understanding the effects of these changes upon society's welfare is an important and useful endeavor. However, modeling the supply side of the hospital industry is inherently difficult due to the nonlinear nature of important supply-side phenomena such as entry, exit, and changes in ownership. Thus, sophisticated econometric modeling of the hospital industry has focused almost exclusively upon the demandside effects of these policy changes.

In this paper we develop and estimate a fully dynamic, structural model of the market for inpatient hospital services. The ultimate objective of this research is to forge a better methodology for predicting the effects of policy and other institutional changes upon aggregate hospital behavior and, through that, on patient welfare. Our framework incorporates both a discrete-choice model of patient demand for inpatient hospital services and a dynamic model of the supply of hospital services which allows for exit, entry, and investment. In the model, consumer and firm behavior depends on several unknown parameters, which we estimate using structural econometric techniques. We then use the estimated parameters to perform policy experiments that illustrate the power of a dynamic equilibrium model.

On the supply side, hospitals compete through their pricing, entry, exit, and investment decisions. Markets for hospital services are primarily local and are most often characterized by a small number of hospitals; thus we model the hospital industry in a game-theoretic setting. Hospitals choose rational strategies that incorporate dynamic optimizing behavior given the actions taken by their competitors.

We try to make the model as realistic as computationally feasible in several ways. The quality of hospitals can vary, and hospitals invest in a stochastic R\&D process in order to increase their quality. In addition, incumbent hospitals can exit the industry at any time and receive a scrap value, while new hospitals can enter at any time by paying some sunk cost of entry. While hospitals are free to set the price they charge on the private market, they must provide free care to indigent patients and must accept payment for Medicare patients according to

1. The dynamic framework of our paper applies and extends Ericson and Pakes (1995). 
regulated rates. Finally, we assume that there are two types of hospitals, for-profits (FPs) and nonprofits (NPs), and that the ratio between them is endogenously determined through entry and exit.

In our model, there are three differences between FPs and NPs. First, FP hospitals maximize expected net profits, while NP hospitals maximize some combination of net profits and quality, where the relative weights NPs put upon quality and profits are estimated. ${ }^{2}$ Second, as federal and local tax codes often give NP institutions tax-exempt status, we specify that FP hospitals must pay property and corporate income taxes, while NP hospitals do not. ${ }^{3}$ Third, as NPs cannot issue equity and their bonds are tax-exempt, we allow NPs and FPs to have differing cost of capital, where we again estimate the relative cost of capital for NPs and FPs. ${ }^{4}$

On the demand side, we impose a discrete-choice framework with heterogeneous agents. An agent is a patient with some illness who must choose between the "outside alternative" and being admitted to any particular hospital in her area. ${ }^{5}$ We specify that the utility that a patient receives from inpatient treatment depends upon the quality of the hospital and the characteristics of the patient. The characteristics of potential patients differ along two lines. First, the type of insurance coverage, and therefore the out-of-pocket expense, varies across patients: patients either have private insurance, have Medicare/Medicaid, or are uninsured. Second, income differs across individuals, and, as in the data, the distribution of income differs according to type of insurance.

The specification of our model is contingent on parameters that characterize hospital technologies, hospital objective functions, consumer preferences, and governmental policies. Where possible, we fix parameters by substituting their empirically observable analogs for 1991 (e.g. Medicare reimbursement levels, tax rates, and income distribution). The remaining parameters are estimated using a structural econometric estimation technique. Our estimation algorithm is as follows. Conditional on a vector of the unobservable parameters, we com-

2. There is support in the literature for this view of the objective function of NP hospitals. For instance, Newhouse (1970) proposed a similar type of objective function for NP hospitals, and there is some empirical evidence justifying this assumption; see for instance Hoerger (1991) and Dranove (1988).

3. IRS 501.3(c) organizations are exempt from paying corporate income taxes, and they can issue tax-exempt bonds. In many local jurisdictions NP institutions are exempt from paying property taxes.

4. Wedig et al. (1989) provide empirical evidence that capital costs vary substantially for NP and FP hospitals.

5. We assume that the outside alternative for a patient is receiving outpatient treatment, drug therapy, or no treatment at all. 
putationally solve for a Markov-perfect Nash equilibrium of our model and then use the equilibrium behavior to evaluate the predictions of the model as to admissions per patient, expenditures per patient, ratio of FPs to NPs, etc. We then search in the parameter space in order to most closely match these predictions to 1991 aggregate statistics of these variables, as provided by the American Hospital Association (AHA) and the Health Care Financing Administration (HCFA). We formalize the search criteria and the confidence intervals of the parameters by using generalized method of moments (GMM) techniques. ${ }^{6}$ To the best of our knowledge, this is the first work that attempts to fit a dynamic, multiple-agent model of an industry to data using a fully dynamic estimation process. Therefore, the methods we present here may be of use to researchers interested in estimating the dynamic behavior of other industries.

In general, the parameters are of the expected sizes and magnitudes. In addition, the model predicts behavior that fits the patterns of the data reasonably well. For instance, in equilibrium, both types of hospitals (NPs and FPs) often, but not always, coexist. NPs also last longer than FPs, earn more profits over their lifetimes, have smaller price/cost margins, are of higher quality than FPs, and are larger. Previous models of health-care provision have suggested that the existence of NP hospitals may be due to asymmetric information (Hansmann, 1980) or the provision of public goods (Weisbrod, 1975). However, in our model, the differences in the objective functions and treatments under the tax code between NPs and FPs is sufficient to obtain equilibria where both types of firms exist and where each type plays a different role.

As the purpose of our model is to serve as a policy tool, we have examined the predictions of the model as to the consequences of different health-care programs. We stress that as this is the first dynamic, game-theoretic model of the hospital industry, the estimation process and hence the parameters used to derive the policy predictions are preliminary, and so one should not use these predictions as a direct guide for policies. Rather, these predictions serve two purposes: first, they show what sort of policies can be analyzed with this model, and second, they illustrate how a dynamic, structural model such as ours will capture the unintended effects of policies that result in their outcomes often being different from what policymakers had originally intended. We examine three different policy changes: the 1984 change in Medicare reimbursements from a retrospective to a prospective pay- 
ment system (RPS and PPS, respectively), universal health-care coverage as in the proposed 1994 Health Reform Act of the Clinton Administration, and taxing nonprofit hospitals. Our model predicts that these policies often have unintended effects because they change industry structure by altering the relative profitabilities of entry, exit, and investment. For instance, we find that lowering Medicare reimbursement rates has indirectly caused hospitals to shift costs onto privately insured patients and that universal health-care coverage can either be beneficial or harmful depending on the method used to fund it, because the funding method alters the industry structure.

The rest of the paper has the following structure. Section 2 describes the model in detail; Section 3 discusses the data and estimation process; Section 4 characterizes the behavior of the estimated model; Section 5 details the policy experiments; and Section 6 concludes.

\section{THE MODEL}

For our model, we consider the market to be a metropolitan area. We are solving for the dynamic equilibrium of the hospital industry where we express the hospital problem in discrete time. In each period, the following occurs. First, each hospital simultaneously decides whether or not to exit. Next, each active hospital simultaneously decides how much to invest. Third, new hospitals decide whether or not to spend a sunk entry cost to build a hospital, which will be ready to accept patients in the next period. Next, each active hospital simultaneously decides what price to charge non-Medicare patients, and finally, patients choose which hospital to be admitted to, if any. In this section, we discuss the patient's decision, the hospital's static production decision, and the hospital's dynamic investment, exit, and entry decisions.

\subsection{PATIENT'S DECISION}

In our model, potential patients have three different types of insurance: Medicare (MD), private insurance (PI), or no insurance, the uninsured (UI). For expositional ease we will refer to individuals enrolled in insurance plans as patient types. In any given locale, there is a fixed population, $M$, of which a proportion of each type of patient, $\Theta_{\mathrm{MD}}, \Theta_{\mathrm{PI}}$, and $\Theta_{\mathrm{UI}}$, is ill and could benefit from inpatient hospital care. For example, the total number of uninsured ill people is given by $\Theta_{\mathrm{UI}} M$.

There are two differences between insurance types. First, the distribution of income is different for each type. We denote the income of each patient $i$ of each type as $Y_{i}^{\mathrm{MD}}, Y_{i}^{\mathrm{PI}}$, and $Y_{i}^{\mathrm{UI}}$. Second, each insurance plan has a different arrangement for payment of medical services. 
Hospital $j$ is free to set $p_{j}^{N M}$, the base price that it charges for nonMedicare patients, at any reasonable value it wishes, while it accepts as given the Medicare reimbursement rate $p^{\mathrm{M}}$. A MD patient must pay a fixed deductible, $d$, for each hospital visit (while the government pays $p^{\mathrm{M}}$ to cover the rest); a PI patient must pay a copayment for each hospital visit, which is a percentage, $c$, of the total cost of her hospital bill $p_{j}^{\mathrm{NM}}$; and a UI patient must pay her full medical bill.

There is an exception to the above payment levels: indigent patients do not necessarily have to pay the full list price for the services they receive. Under the Emergency Medical Treatment and Active Labor Law of 1986, hospitals are required to treat patients in emergency situations (at least until they are stabilized) regardless of their ability to pay. For this reason, we specify that hospitals cannot turn away patients and they can only charge a patient so much that her income does not fall below some threshold, $Y_{\mathrm{MIN}}$, regardless of patient type. (If a patient already has income below $Y_{\mathrm{MIN}}$, then the hospital cannot charge her anything.) Thus, we can write the price that each patient of each type must pay as follows:

$$
\begin{aligned}
p_{i j}^{\mathrm{MD}} & =\max \left\{\min \left\{d, Y_{i}^{\mathrm{PI}}-Y_{\mathrm{MIN}}\right\}, 0\right\}, \\
p_{i j}^{\mathrm{PI}} & =\max \left\{\min \left\{c p_{j}^{\mathrm{NM}}, Y_{i}^{\mathrm{PI}}-Y_{\mathrm{MIN}}\right\}, 0\right\}, \\
p_{i j}^{\mathrm{UI}} & =\max \left\{\min \left\{p_{j}^{\mathrm{NM}}, Y_{i}^{\mathrm{UI}}-Y_{\mathrm{MIN}}\right\}, 0\right\} .
\end{aligned}
$$

We model a patient's choice of hospital as a differentiated-products discrete-choice problem and assume that the utility that each patient $i$ of insurance type $T$ (where $T$ can be MD, PI, or UI) receives from visiting a hospital $j$ is dependent on the quality, $k_{j}$, of that hospital, her out-of-pocket expense, $p_{i j}^{T}$, her income, $Y_{i}^{T}$, and an error term. In our view, a hospital's quality can be characterized by its level of physical capital (e.g. MRIs, testing labs, etc.), human capital (e.g. more and better-quality physicians and nurses, etc.), and unobservable components. ${ }^{7}$ Increased quality affects a patient's utility function by increasing the probability that the patient will recover from the illness that he has when entering the hospital, and by making the patient's stay at the hospital more pleasant. In this model, we examine hospital quality in reduced form and abstract away from the issue of what exactly characterizes quality and how this affects patient utility.

7. In actuality, hospital quality may vary by type of illness. In particular, different hospitals are known to specialize in specific types of illness. Because of its complexity we are not considering this multidimensional aspect of quality. 
Specifically, we write the utility for patient $i$ of type $T$ choosing hospital $j$ as

$U_{i j}^{T}=k_{j}+\gamma_{1} \ln \left(Y_{i}^{T}-\gamma_{2} p_{i j}^{T}\right)+\varepsilon_{i j}^{T}$,

where the error term $\varepsilon_{i j}^{T}$ is i.i.d. across patients, hospitals, and types and has a double exponential or type I extreme-value distribution, and $\gamma_{1}$ and $\gamma_{2}$ are parameters. Each patient also has an outside alternative, option 0 , which consists of outpatient care, drug treatment, or no treatment. We normalize $k_{0}=0$, define $p_{0}$ to be the price of the outside good, and obtain

$U_{i 0}^{T}=\gamma_{1} \ln \left(Y_{i}^{T}-\gamma_{2} p_{0}\right)+\varepsilon_{i 0}^{T}$,

where again $\varepsilon_{i 0}^{T}$ is distributed as a double exponential. We choose this specification for two reasons. First, it allows for a heterogeneous response to an increase in quality, both because there are different types of patients and because patients of the same type have different income levels. Second, it allows for the effect of a price increase to be smaller for individuals of higher income.

In order to calculate the market equilibrium, we need to know profit levels for firms, which depend on market shares. Because of our choice of double-exponential or logit error term, we can analytically evaluate the probability of patient $i$ of type $T$ choosing hospital $j$ using the standard logit share formula. We subtract the utility of the outside alternative in $(2 b)$ from the utility in $(2 a)$ to obtain:

$$
\begin{aligned}
s_{i j}^{T}\left(p_{i j}^{T}\right) & =\int_{U_{i j}^{T}>U_{i k}^{T} \forall k=0, \ldots, k^{\neq} \neq} S_{j i j}^{T}\left(\varepsilon \mid p_{i j}^{T}\right) d P(\varepsilon) \\
& =\frac{\exp \left[k_{j}+\gamma_{1} \ln \left(\frac{Y_{i}^{T}-\gamma_{2} p_{i j}^{T}}{Y_{i}^{T}-\gamma_{2} p_{0}}\right)\right]}{1+\sum_{k=1}^{J} \exp \left[k_{k}+\gamma_{1} \ln \left(\frac{Y_{i}^{T}-\gamma_{2} p_{i k}^{T}}{Y_{i}^{T}-\gamma_{2} p_{0}}\right)\right]} .
\end{aligned}
$$

In addition to shares, we are interested in finding welfare in order to evaluate the effects of different policies. In order to compute welfare, we need to be able to compare the dollar value of the consumer surplus to the profits and government expenditures that result from any industry structure. Our choice of logistic error terms on the utility lets us express the expected utility of consumer $i$ of type $T$ as $^{8}$ 
$E U_{i}^{T}=\ln \left\{1+\sum_{k=1}^{J} \exp \left[k_{k}+\gamma_{1} \ln \left(\frac{Y_{i}^{T}-\gamma_{2} p_{i j}^{T}}{Y_{i}^{T}-\gamma_{2} p_{0}}\right)\right]\right\}$,

where $p_{i j}^{T}$ is the price paid by that consumer. To obtain the dollar value of consumer surplus, we use an approximation technique suggested by McFadden (1981), which is to divide the expected utility from (4) by the marginal utility of income. Additionally, to compare consumer surplus across policy experiments, we must take into account the fact that different policy experiments will result in different total bills being paid by insurance companies, because patients do not pay the full cost of their care. Thus, when the price of hospital services increases, we must include not just the additional price paid by sick patients but also the additional bill paid by the insurance companies on behalf of these patients. We factor in the additional insurance costs by assuming a breakeven condition for insurance companies, and by subtracting the additional cost of insurance from the consumer surplus of privately insured patients.

\subsection{Hospital's Static Production Decision}

At any time $t$, there are $N_{t}$ hospitals present in the market, where $N_{t}$ will vary with entry and exit. Each hospital may be a NP or a FP hospital. In addition to its operating type, each hospital has some quality $k_{j}$. (Recall that hospital quality affects patient utility). We further specify that each hospital $j$ has identical fixed costs, $F$, that it must pay each period, but differing marginal costs $\mathrm{mc}_{j}$ that are constant for each hospital but that vary with the quality of the hospital. Thus, we write

$\mathrm{mc}_{j}=\overline{\mathrm{mc}}+b k_{j}$.

Given marginal costs from (5), market shares from (3), and prices from (1), we can write gross variable profits as

$$
\begin{aligned}
\pi_{j}^{\mathrm{GV}}\left(p^{\mathrm{NM}}\right)= & M\left(\Theta_{\mathrm{MD}} \int s_{i j}^{\mathrm{MD}}\left(p^{\mathrm{MD}}+p_{i j}^{\mathrm{MD}}-\mathrm{mc}_{j}\right) d P\left(Y^{\mathrm{MD}}\right)\right. \\
& +\Theta_{\mathrm{PI}} \int s_{i j}^{\mathrm{PI}}\left(p^{\mathrm{NM}}\right)\left[(1-c) p_{j}^{\mathrm{NM}}+c p_{i j}^{\mathrm{PI}}-\mathrm{mc}_{j}\right] d P\left(Y^{\mathrm{PI}}\right) \\
& \left.+\Theta_{\mathrm{UI}} \int s_{i j}^{\mathrm{UI}}\left(p^{\mathrm{NM}}\right)\left(p_{i j}^{\mathrm{UI}}-\mathrm{mc}_{j}\right) d P\left(Y^{\mathrm{UI}}\right)\right),
\end{aligned}
$$

where $p^{\mathrm{NM}}$ is the vector of prices for non-Medicare patients.

Recall that there are three differences between NP and FP hospitals. First, NP hospitals do not care solely about profits, but they also value the quality of care that they provide. Accordingly, we specify 
that NPs put a weight of $\alpha_{P}$ on profits in their objective function, and a weight of $\alpha_{C}+\alpha_{Q} k_{j}$ on their quality, where we would expect $\alpha_{C}$ to be negative. Second, FP hospitals are taxed: they pay corporate income tax on profits at a rate of $\tau_{I}$, and property tax on their fixed based $S$ (which we assume is the same as the sunk entry cost) at a rate of $\tau_{P}$. Third, FP and NP hospitals pay different amounts, $c_{I}^{\mathrm{FP}}$ and $c_{I}^{\mathrm{NP}}$ respectively, per unit of investment, to reflect their different costs of capital. We can now use (6) and the above differences between FPs and NPs to write the static objective functions of FP and NP hospitals as

$$
\begin{aligned}
\mathrm{OBJ}_{j}^{\mathrm{FP}}\left(p^{\mathrm{NM}}\right)= & {\left[\pi_{j}^{\mathrm{GV}}\left(p^{\mathrm{NM}}\right)-F-\tau_{p} S-c_{I}^{\mathrm{FP}} x_{j}\right] } \\
& -\tau_{I} \max \left\{0,\left(\pi_{j}^{\mathrm{GV}}\left(p^{\mathrm{NM}}\right)-F-\tau_{p} S-c_{I}^{\mathrm{FP}} x_{j}\right)\right\}, \\
\mathrm{OBJ}_{j}^{\mathrm{NP}}\left(p^{\mathrm{NM}}\right)= & \alpha_{P}\left(\pi_{j}^{\mathrm{GV}}\left(p^{\mathrm{NM}}\right)-F-c_{I}^{\mathrm{NP}} x_{j}\right)+\alpha_{Q} k_{j}+\alpha_{C},
\end{aligned}
$$

where $x_{j}$ is the chosen level of investment and will be further discussed in Section 2.3.

Now that we have detailed the static objectives of firms, we illustrate our strategy for solving for the equilibrium vector of prices. As we are searching for a Markov-perfect Nash equilibrium (MPNE) of our model as in Maskin and Tirole (1988a, b), we are restricting strategies to be a function of payoff-relevant states. Since current-period prices do not affect future payoffs, they do not affect future states; hence each hospital chooses $p_{j}^{\mathrm{NM}}$ to maximize its static objective function from (7). Thus, to solve for the MPNE of our model, we need first to solve for a static Nash equilibrium in prices for every vector of hospital qualities and costs. Caplin and Nalebuff (1991) provide conditions for discretechoice models under which there exists a unique Nash equilibrium in prices. Our model satisfies these conditions, provided that there is some bound on prices. ${ }^{9}$

Nash equilibrium conditions imply that an equilibrium will exist at a vector of prices that simultaneously maximizes (7) for each hospital. We can further simplify the problem to consider maximizing only gross variable profits from (6), as the price that maximizes gross variable

9. If prices were allowed to be arbitrarily high, then firms would choose to price infinitely high, as shares would be bounded away from zero because the insurance companies would pay their portion of the bill while the minimum-income condition would limit the out-of-pocket expense of the privately insured patient. This is why we need a bound on prices. 
profits will also maximize the static objective function. ${ }^{10}$ While we still cannot analytically maximize the vector of equations (6), we can numerically maximize them by differentiating the $N_{t}$-dimensioned vector of equations (6) and then using a computer algorithm to search for the solution to the $N_{t}$-dimensional vector of FOCs. We differentiate (6) as follows: first, we can analytically find the derivative $d \pi_{i j}^{T, \mathrm{GV}} / d p_{j}^{\mathrm{NM}}$ because of our logit assumption. To get $d \pi_{j}^{\mathrm{GV}} / d p_{j}^{\mathrm{NM}}$ from $d \pi_{i j}^{T, \mathrm{GV}} / d$ $p_{j}^{\mathrm{NM}}$, we must then differentiate the integral of $\pi_{i j}^{\mathrm{GV}}$ over the measure of patient income. We can apply Lebesgue's dominated-convergence theorem to interchange the derivative and the integral and write this as

$$
\begin{aligned}
& \frac{d \pi_{j}^{\mathrm{GV}}}{d p_{j}^{\mathrm{NM}}}\left(p^{\mathrm{NM}}\right)=M\left(\Theta_{\mathrm{PI}} \int \frac{d \pi_{i j}^{\mathrm{PI}, \mathrm{GV}}}{d p_{j}^{\mathrm{NM}}} d P\left(Y^{\mathrm{PI}}\right)+\Theta_{\mathrm{UI}} \int \frac{d \pi_{i j}^{\mathrm{UI}, \mathrm{GV}}}{d p_{j}^{\mathrm{NM}}} d P\left(Y^{\mathrm{UI}}\right)\right) \\
& =M\left(\Theta _ { \mathrm { PI } } \left\{\left\{1\left\{p_{i j}^{\mathrm{PI}}<p^{\mathrm{NM}}\right\}(1-c) s_{i j}^{\mathrm{PI}}+1\left\{p_{i j}^{\mathrm{PI}}=p^{\mathrm{NM}}\right\}\right.\right.\right. \\
& \left.\times\left[s_{i j}^{\mathrm{PI}}\left(p^{\mathrm{NM}}\right)-\gamma_{1}\left(p_{j}^{\mathrm{NM}}-\mathrm{mc}_{j}\right) s_{i j}^{\mathrm{PI}}\left(1-s_{i j}^{\mathrm{PI}}\right)\left(\frac{Y_{i}-\gamma_{2} c p_{j}^{\mathrm{NM}}}{Y_{i}-\gamma_{2} p_{0}}\right)^{-1} \gamma_{2} c\right]\right\} \\
& \times d P\left(Y^{\mathrm{PI}}\right)+\Theta_{\mathrm{UI}} \int 1\left\{p_{i j}^{\mathrm{UI}}=p^{\mathrm{NM}}\right\} \\
& \left.\times\left[s_{i j}^{\mathrm{UI}}\left(p^{\mathrm{NM}}\right)-\gamma_{1}\left(p_{j}^{\mathrm{NM}}-\mathrm{mc}_{j}\right) s_{i j}^{\mathrm{UI}}\left(1-s_{i j}^{\mathrm{UI}}\right)\left(\frac{Y_{i}-\gamma_{2} p_{j}^{\mathrm{NM}}}{Y_{i}-\gamma_{2} p_{0}}\right)^{-1} \gamma_{2}\right] d P\left(Y^{\mathrm{UI}}\right)\right) .
\end{aligned}
$$

Here, $1\{\cdot\}$ denotes the indicator function that takes on the value of one if the condition inside the brackets is true, and zero otherwise.

\subsection{HOSPITAL'S DYNAMIC DECISION}

As we have characterized prices and production, we now characterize the choice of the dynamic variables of entry, exit, and investment. The dynamic model that we use is a variant of the model proposed in Ericson and Pakes (1995) and solved numerically in Pakes and McGuire (1994). This class of models describes an infinite-horizon discrete-time industry with endogenous entry, exit, and investment, where firms

10. For NP firms, this is easy to verify, because the difference between the gross variable profits and the objective function is only one of scale. For FP firms, this holds as well, for the following reasons: if pretax total profits are positive, then the objective function is $1-\tau_{1}$ times the pretax total profits locally, so this holds; if pretax total profits are negative, then the objective function is just the pretax total profits, locally, so this again holds; finally, if pretax profits are zero, then as any small change in price would decrease gross variable profits, any small change in price would also decrease the objective function, so we are at a maximum. 
choose strategies in order to maximize the expected discounted value (EDV) of their net future profits given their information and some common discount rate $\beta$. As this is a dynamic game model, equilibrium occurs when firms are maximizing their EDV of profits assuming that their present and potential competitors will play their equilibrium strategies, and equilibrium obeys rational expectations. This model is solved contingent on the state space. As the state space must be payoffrelevant, per Maskin and Tirole (1988a, b), a state in our model specifies the quality (and hence marginal cost) for each firm in the industry. We now detail the exit, investment, and entry processes.

At the beginning of every period, firms decide whether or not to exit. Each firm simultaneously receives an i.i.d. scrap value draw from a uniform distribution $U\left(\Phi-\sigma_{\Phi}, \Phi+\sigma_{\Phi}\right)$, and immediately decides whether to accept its scrap value draw and exit forever or stay active in the current period. If a FP hospital exits, it can only keep a proportion $\tau_{I}$ of the scrap value; similarly, if a NP hospital exits, it would only value the scrap value at a proportion $\alpha_{p}$, because the scrap value is essentially a net profit.

After the exit process, the remaining incumbents simultaneously invest. At time $t$, each firm $j$ can choose to invest any nonnegative amount $x_{j t}$ at a cost of $c_{I}^{\mathrm{FP}}$ or $c_{I}^{\mathrm{NP}}$, depending on its ownership status. We assume that firm $j$ invests to increase efficiency $w_{j}$ and that efficiency translates into quality $k_{j}$ through a function $g\left(w_{j}\right)$. The functional form we choose for $g\left(w_{j}\right)$ is

$$
\begin{aligned}
k_{j} & =g\left(w_{j}\right) \\
& = \begin{cases}w_{j} & \text { if } w_{j} \leq w^{1}, \\
\ln \left(\exp \left(w^{1}\right)\left\{w^{2}-\exp \left[-\left(w_{j}-w^{1}\right)\right]\right\}\right) & \text { otherwise, }\end{cases}
\end{aligned}
$$

for parameters $w^{1}$ and $w^{2}$. This functional form allows for quality to grow linearly in efficiency at first, but then to grow increasingly more concave for higher levels of efficiency. We choose this specification because the increasing concavity of returns to efficiency is necessary to ensure that firms do not want to increase their efficiency without bound.

In our model, the gain in efficiency from increased investment is stochastic. In particular, if a firm has efficiency $w_{j t}$ at time $t$, then its efficiency at time $t+1$ is

$w_{j, t+1}=w_{j t}+v_{j t}-\bar{v}_{t}$,

where $v_{j t}$ is the return to the firm's own R\&D and $\bar{v}_{t}$ represents the possibility of the outside alternative increasing. As in Pakes and McGuire (1994), these variables have distributions of 


$$
\begin{aligned}
& v_{j}= \begin{cases}1 & \text { with prob. } a x_{j t} /\left(1+a x_{j t}\right), \\
0 & \text { with prob. } 1 /\left(1+a x_{j t}\right),\end{cases} \\
& \bar{v}= \begin{cases}1 & \text { with prob. } \delta, \\
0 & \text { with prob. } 1-\delta .\end{cases}
\end{aligned}
$$

We motivate this type of investment function as follows: $v_{j t}$ represents hospital-specific efficiency gains, which are uncertain, and $\bar{v}$ represents the outside options to hospital treatment (e.g. drug treatment or outpatient treatment), which increase stochastically over time. The fact that the hospital industry is characterized by uncertainty and rapid technological change justifies this choice of industry dynamics.

Following the investment process, the entry process occurs. At this time, two potential entrants, one NP and one FP, each receive a draw of a sunk cost of entry from the distribution $U\left(S-\sigma_{S}, S+\sigma_{S}\right)$. If the entrant pays its draw, it can enter in the following period with an initial efficiency $w_{E}-\bar{v}_{t}$. We assume that some regulator is issuing a certificate of need which is necessary for a hospital to enter, and that entry is limited to one hospital in each period. The regulator will allow entry only if the entrant has a positive EDV of future profits from entering. In that case, the hospital that will be allowed to enter is the one which has the higher EDV of future profits from entering. Because the EDV of future profits from entering includes the sunk-entry-cost draw, the equilibrium outcome of the entry process (i.e. no entry, NP entry, or FP entry) may be random, even for the same state.

As shown in Ericson and Pakes (1995), there exist some minimum and maximum efficiency levels that firms will never reach with positive probability. Additionally there exists at least one equilibrium for this type of model. Although Ericson and Pakes (1995) do not guarantee the uniqueness of the equilibrium, they do prove various other properties, including the existence of a recurring class of industry structures that will occur in equilibrium and an ergodic distribution of probabilities of occurrence for each of these industry structures in the recurring class. It is easy to prove that similar properties to those of the Ericson and Pakes (1995) model hold for our model. Conditional on a vector of parameters, we use dynamic programming methods to solve for an equilibrium of this industry. Because of the ergodic properties of the model and the efficiency bounds, we can meaningfully compute the model in a compact state space and talk about the long-run, or ergodic, equilibrium mean values of variables of interest. The reader may consult Gowrisankaran and Town (1995) for details of the dynamic solution algorithm, and Pakes et al. (1993) for general methodology on solving this type of model. 
TABLE I.

THE PARAMETERS OF THE MODEL ${ }^{a}$

\begin{tabular}{|c|c|c|c|c|c|}
\hline \multicolumn{3}{|c|}{ Demand and Policy Parameters } & \multicolumn{3}{|c|}{ Firm Parameters } \\
\hline Param. & Explanation & Value & Param. & Explanation & Value \\
\hline M & Population & 250,000 & $\beta$ & Discount rate & 0.925 \\
\hline$\Theta_{\mathrm{MD}}$ & Ill Medicare patients & $0.0652 \%$ & $\sigma_{\phi}$ & Spread of scrap-value distribution & $\$ 2 \mathrm{M}$ \\
\hline$\Theta_{\mathrm{PI}}$ & $\begin{array}{l}\text { Ill privately ins. } \\
\text { patients }\end{array}$ & $0.0784 \%$ & $\begin{array}{l}\sigma_{s} \\
W_{E}\end{array}$ & $\begin{array}{l}\text { Spread of entry-cost distribution } \\
\text { Initial efficiency of potential }\end{array}$ & $\begin{array}{l}\$ 10 \mathrm{M} \\
\quad 4\end{array}$ \\
\hline \multirow[t]{2}{*}{$\Theta_{\mathrm{UI}}$} & Ill uninsured & $0.0174 \%$ & & entrant & \\
\hline & patients & & $\alpha_{p}$ & NP value from profits & 0.789 \\
\hline \multirow[t]{2}{*}{$Y_{\mathrm{MIN}}$} & Threshold income & $\$ 5000$ & & & $(0.298)$ \\
\hline & $\begin{array}{l}\text { for free care } \\
\text { provision }\end{array}$ & & $\alpha_{Q}$ & $\begin{array}{l}\text { NP increment in value from } \\
\text { quality }\end{array}$ & $\begin{array}{r}935 \\
(672)\end{array}$ \\
\hline$p_{0}$ & $\begin{array}{l}\text { Price of outside } \\
\text { alternative }\end{array}$ & $\$ 0$ & $\alpha_{C}$ & NP base value from quality & $\begin{array}{l}-1641 \\
(747)\end{array}$ \\
\hline \multirow{4}{*}{$\begin{array}{l}c \\
d \\
P^{\mathrm{MD}}\end{array}$} & Copayment rate & 0.2 & $\overline{\mathrm{mc}}$ & Marginal cost for base-quality & $\$ 5096$ \\
\hline & Medicare deductible & $\$ 628$ & & hospital & (\$137) \\
\hline & $\begin{array}{l}\text { Medicare } \\
\text { reimbursement }\end{array}$ & $\$ 5450$ & $b$ & Increment in mc with quality & $\begin{array}{c}\$ 314 \\
(\$ 148)\end{array}$ \\
\hline & rate & & $F$ & Fixed cost of operation & $-\$ 501 \mathrm{k}$ \\
\hline \multirow[t]{2}{*}{$\tau_{I}$} & Corporate income & 0.4 & & & $(\$ 88$ k) \\
\hline & tax rate & & $c_{I}^{\mathrm{FP}}$ & Cost of one unit of investment & $\$ 790 \mathrm{k}$ \\
\hline \multirow[t]{2}{*}{$\tau_{P}$} & Corporate property & 0.01 & & for FPs & (\$1127 k) \\
\hline & tax rate & & $c_{I}^{\mathrm{NP}}$ & Cost of one unit of investment & $\$ 569 \mathrm{k}$ \\
\hline \multirow[t]{2}{*}{$\gamma_{1}$} & Income elasticity & 20.6 & & for NPs & (\$687 k) \\
\hline & & $(23.2)$ & $\delta$ & Probability of outside alternative & 0.553 \\
\hline \multirow[t]{6}{*}{$\gamma_{2}$} & Price elasticity & 3.79 & & rising & $(0.015)$ \\
\hline & & (3.36) & $a$ & $\begin{array}{l}\text { Param. in stochastic investment } \\
\text { return fn. }\end{array}$ & $\begin{array}{c}0.510 \\
(0.706)\end{array}$ \\
\hline & & & $\Phi$ & $\begin{array}{l}\text { Mean scrap value for an existing } \\
\text { hospital }\end{array}$ & $\begin{array}{l}-\$ 42 \mathrm{M} \\
(\$ 7.2 \mathrm{M})\end{array}$ \\
\hline & & & $S$ & $\begin{array}{l}\text { Mean sunk cost of entry for a } \\
\text { new hospital }\end{array}$ & $\begin{array}{l}-\$ 1.1 \mathrm{M} \\
(\$ 1.1 \mathrm{M})\end{array}$ \\
\hline & & & $w^{1}$ & $\begin{array}{l}\text { Inflection point for eff./quality } \\
\text { mapping }\end{array}$ & $\begin{array}{l}1.0 \\
(3.34)\end{array}$ \\
\hline & & & $w^{2}$ & $\begin{array}{l}\text { Rate of concavity for eff./quality } \\
\text { mapping }\end{array}$ & $\begin{array}{c}3.61 \\
(7.32)\end{array}$ \\
\hline
\end{tabular}

${ }^{a}$ Estimated parameters are in bold; standard errors in parentheses.

\section{Data AND Estimation of the Model}

As outlined above, the model is dependent on the values of several parameters. While some of the parameters are directly observable, others must be econometrically estimated. Table I lists the parameters and their chosen values; the unobservable parameters are listed in bold, with standard errors underneath. We split the remainder of this section into a discussion of how we obtain the observable parameters and how we estimate the unknown parameters. 


\subsection{Observable Parameters}

On the demand side, we choose to examine hospitals where the population size for the market (i.e. $M$ ) is 250,000 . We choose this population size because there are many hospitals (over 500) in metropolitan areas in the United States with population between 100,000 and 500,000 and because metropolitan areas of this size typically have less than three hospitals, which makes the equilibrium computation quicker. While we estimate our model using 1991 data, one could conceivably estimate the model with more than one year of data. The copayment rate $c$ is chosen to reflect the typical out-of-pocket expense for insured individuals. The parameter $Y_{\mathrm{MIN}}$ is chosen to be roughly half of the poverty line, and $p_{0}$ is chosen to be 0 , to reflect the outside alternative being no treatment, or very inexpensive treatment.

Recall that we need to know the income distribution for each type of patient to compute market shares. We use the March, 1991 CPS to obtain data on the family income for each individual, the type of insurance each person is enrolled in (if any), and the sampling weight for each individual. ${ }^{11}$ We let the universe be the set of people with no military insurance and define MD patients to be the set of people who had Medicare or Medicaid insurance, PI patients to be those who had insurance but did not have Medicare or Medicaid insurance, and UI people to be those who did not have any insurance. Many people responded that they had both Medicare and private insurance. We treat these people as being of type MD, for it is likely that the private insurance was a Medigap policy and that a hospital's main source of reimbursement for these patients was the Medicare system. To obtain the conditional distribution of income, then, we sample the CPS using the weights provided to construct income quantiles for each type. We then integrate out over this distribution to find market shares by using quadrature.

Another demand observable that we require is the percentage of the total population with each type of insurance (private, Medicare/ Medicaid, and uninsured) who are ill and could benefit from hospital treatment. We compute these $\Theta$ parameters as follows: we again use the Current Population Survey (CPS) from March 1991, this time to obtain the percentage of Americans with each type of insurance, and

11. We note additionally that the CPS has other information that can be used with our model to estimate the effects of policy changes on particular segments of the population. For instance, the CPS contains information on each person's age, race, and sex, and whether the person lives in an urban location. Thus, we can easily use our model to predict the effects of policies on ethnic, racial, or age groups in the population. 
the mean income for each type. Manning et al. (1987) estimated the probability of being admitted to a hospital as a function of the cost of health care and income. For PI and UI patients, we approximate the conditional probability of being sick by Manning's probability of being admitted to a hospital given a zero cost and the mean income level of their patient types. For MD patients (who are not discussed in Manning's study), we again use hospitalization rates, here as provided by the Health Care Financing Administration (1993), as a proxy for rates of illness, because of the zero coinsurance cost of the federal programs. To compute each $\Theta$ then, we multiply the marginal probability of type of insurance (from the CPS) by the conditional probability of being sick given that type [from Manning et al. (1987) and the Health Care Financing Administration (1993)].

On the supply side, the discount rate $\beta$ is chosen to be a standard discount or interest rate. Although we estimate the means of the sunkentry-cost and exit-scrap-value distributions, we do not estimate the spreads of the distributions, $\sigma_{S}$ and $\sigma_{\Phi}$ respectively, because these spreads are chosen largely to ensure convergence. Thus, we simply pick values that are small enough so that they do not significantly influence the results but large enough to ensure convergence of the algorithm. The only other supply-side parameter that is not estimated is $w_{E}$, the efficiency level of the potential entrant. We do not estimate $w_{E}$ because we do estimate the sunk cost of entry, and the effect of the two parameters would be highly collinear. Thus, we simply normalize $w_{E}$ to 4 .

On the policy side, in 1991, the Medicare hospital deductible was $\$ 628$. In 1991, the average Medicare payout to hospitals was $\$ 5,450$ per admission; ${ }^{12}$ this determined our choice of $p^{\mathrm{MD}}$ and $d$. Business property tax rates vary considerably from city to city. We settle upon a $1 \%$ effective tax rate, as it was representative of the cities we researched. We set the corporate income tax rate at $40 \%$.

\subsection{ThE PARAMETER EStIMATION PROCESS}

The remaining 16 parameters of the model are estimated using a generalized method of moments (GMM) estimation algorithm. The goal of the econometrics is to estimate the real-world values of the parameters by matching the ergodic long-run distribution of industry statistics from the model to real-world aggregate industry statistics. We use aggregate statistics for two reasons. First, for sensitivity reasons, the AHA 
publishes certain hospital information only in aggregate form, and does not list individual hospital values for the information. Second, our dynamic model predicts the ergodic distribution of hospital characteristics conditional on parameters, but cannot easily match individual simulated hospitals to real-world hospitals, as quality is not directly measurable for real-world hospitals.

The aggregate industry statistics we use are obtained from two sources: the 1991 Annual Survey of Hospitals Data Base from the AHA, and the PPS-8 1991 Hospital Cost Report Data from HCFA. ${ }^{13}$ We use as the universe all short-term, general-care hospitals located in metropolitan statistical areas (MSAs) of between 100,000 and 500,000 people; there are over 500 observations. From the AHA, we obtain data on admissions, expenditures, and number of hospitals by ownership type (NP or FP), and payer mix (Medicare/Medicaid or private insurance or self-pay). From HCFA, we obtain data on investment and revenues. With these data, we construct the following statistics: for NP and FP hospitals separately, we calculate admissions per hospital, revenues per admission, expenditures per admission, and investment as a percentage of expenditures; we also use payer mix (for privately insured and Medicare/Medicaid), ratio of FP hospitals to the total, and number of hospitals per MSA. Additionally, we use second-moment terms for revenues, expenditures, and investment, and interaction terms between investment and revenues and between investment and expenditures, all for NP and FP hospitals separately, for a total of 22 aggregate statistics. The second-moment and interaction terms are found by summing over individual hospital characteristics. Thus, for instance, letting revenues per admission for hospital $j$ be denoted by $r_{j}$ and investment as a percentage of expenditures for hospital $j$ be denoted by $i_{j}$, we compute the second moment for revenues as $\sum_{j} r_{j} r_{j}$ and the interaction term as $\sum_{j} r_{j} i_{j}$.

Our estimation algorithm is in the same vein as the dynamic structural estimation methods used by Pakes (1986) and Holmes and Schmitz (1995). The central idea behind all three algorithms is to fix a parameter vector, compute the equilibrium of the model conditional on the parameter vector, simulate the model to find the distribution of predictions of this equilibrium, and then examine how well these predictions match aggregate data. Finally, the algorithms all then search the parameter space to find the parameter vector that causes the

13. We thank Roger Feldman and Bob Conner for making the PPS data available to us. We also thank Bob Conner for allowing us the use of his CONLINK database that matches these two datasets. 
predictions to most closely match the data according to some econometric technique. The main difference between our estimation method and those of these earlier studies is that they use a maximum likelihood (ML) estimation process, while we use GMM. The reason that we use GMM instead of ML is that we observe several different firm characteristics (investment, expenditures, revenues, admissions, etc.) instead of one overall predictor of firm behavior. However, we add in second moments of distributions and interaction terms, in order to get at the distribution of these statistics and not just the means, just as ML would do.

To formalize the estimation, then, the theoretical moment condition that we use is

$G(\Omega)=m(\Omega)-\bar{R}$,

where $m(\Omega)$ is the mean vector of predicted ergodic distribution values of the model for the 22 hospital characteristics listed above, conditional on the parameter vector $\Omega$, and $\bar{R}$ is the mean vector of corresponding values for actual hospitals, if there were an infinite number of hospitals. By assumption, at the true parameter vector, the moment condition will be 0 . This moment condition has the sample analog

$G_{J}(\Omega)=\sum_{j=1}^{J} m_{j}(\Omega)-\bar{R}_{J}$,

where $\bar{R}_{J}$ is the mean vector of aggregate statistics as computed from the data. Our GMM estimation algorithm finds $\hat{\Omega}$ to solve

$\hat{\Omega}=\underset{\Omega}{\arg \min }\left\|G_{J}(\Omega)\right\|$.

Following Hansen (1982), we compute standard errors for the parameters using the standard GMM formulation, with numerical approximations for the derivatives.

While $m_{j}(\Omega)$ is conceptually simple, computing it is quite cumbersome, which is why no previous study has attempted to estimate a dynamic game-theoretic model of an industry. The method that we use to compute $m_{j}(\Omega)$ is as follows. First, we compute the static gross variable profit function for the parameter vector $\Omega$, and then the Markovperfect equilibrium of the entire dynamic model, using this gross variable profit function. Finally, we simulate the model for a large number $(2,000,000)$ of periods. Though we should take $J$ i.i.d. random draws from the simulation in order to satisfy (13) exactly, we instead use the mean of the entire vector of draws in order to reduce the variance. In order to save computation time, we specify a maximum of three firms 
in the industry at any one time; our policy experiments are computed with a maximum of four firms allowed. Even with this maximum, the computational complexity is very large. ${ }^{14}$

\section{Results of the Model}

\subsection{The Model and OBserved Fact}

Table I lists the values and standard errors of the estimated parameters. The parameters are generally of reasonable magnitude and sign. We note that the full-pay demand for health care is quite elastic, and marginal costs increase rapidly with increases in quality, both of which replicate stylized facts about the industry. However, the sunk entry costs appear to be too low, which is a consequence of the fact that we do not observe independent data on these variables with which to estimate our model. Additionally, while the fixed costs of roughly zero might seem low, this is partly because there is also a capital depreciation that is confounded. Table II compares the long-run predictions of our model with some of the aggregate industry behavior that we are attempting to match. The parameters do reasonably well in fitting the model to data. The model is able to accurately predict the number of hospitals, the ratio of NP to FP hospitals, and the payer mix. One prediction that is not very close is the expenditures per patient for FPs relative to NPs: our model predicts that NPs and FPs have similar expenditures per patient, while the data suggests that FPs have higher expenditures per patient. We feel that the PPS data from which we obtained this higher expenditures per patient may be flawed. Furthermore, our model underestimates the percentage of revenues derived from patients who are not privately insured. The reason for this is that our $\theta$ parameters for market shares may be overestimating the percentage of privately insured patients in need of hospital care. As another caveat to our results, we note that the model was estimated using a maximum of three firms in the industry. When we increase the maximum number of firms to four (which can be seen in our results in Table III), the actual number of firms increases substantially. This suggests that this maximum of three firms is leading to inaccuracy in our results. The message that we take from Tables I and II is that our model can generate structures that look similar to the real world. Future estimation

14. On a Pentium P5 133-MHz processor, evaluating the three-firm moment function at one point takes 5 to 10 minutes; evaluating the four-firm moment function at one point takes 40 to 50 minutes. Performing the entire GMM process takes approximately 4 to 5 days. 
TABLE II.

VAlues of THE PREDicted Statistics OF THE ERGOdic DISTRIBUTION OF THE MODEL AND OF THE CORRESPONDING OBSERVED STATISTICS ${ }^{a}$

\begin{tabular}{lcc}
\hline \multicolumn{1}{c}{ Quantity } & Predicted & Real World \\
\hline Revenue per admission (\$) & $\mathrm{NP}, 5,668$ & $\mathrm{NP}, 7,082$ \\
& $\mathrm{FP}, 5,530$ & $\mathrm{FP}, 9,318$ \\
Expenditures per admission (\$) & $\mathrm{NP}, 5,146$ & $\mathrm{NP}, 5,553$ \\
& $\mathrm{FP}, 5,522$ & $\mathrm{FP}, 5,548$ \\
Investment/expenditures (\%) & $\mathrm{NP}, 7.6$ & $\mathrm{NP}, 7.5$ \\
& $\mathrm{FP}, 13.0$ & $\mathrm{FP}, 12.7$ \\
FP/NP hospitals (\%) & 15.9 & 16.0 \\
Average size, by admissions & $\mathrm{NP}, 6676$ & $\mathrm{NP}, 8302$ \\
(patients) & $\mathrm{FP}, 4908$ & 56 \\
Ratio of size (by admissions), & 73.5 & \\
FP/NP (\%) & & Privately insured: 38 \\
Payer mix (\%) & Privately insured: 54 & 2.85 \\
Mean number of hospitals in & Medicare/Medicaid: 46 & Medicare /Medicaid: 53 \\
areas with 100,000 to 500,000 & 2.85 & \\
people & & \\
\hline
\end{tabular}

a 1,000,000-period simulation.

using more detailed and accurate data and more powerful computers can obtain parameter values and hence policy implications more precisely.

Table III lists the characteristics of the base-case long-run distribution, given our estimated parameters; here we are allowing a maximum of four firms in the industry. ${ }^{15}$ We first list the surpluses and government revenues, which will be useful for examining the consequences of policy experiments, and then the firm characteristics. One unfortunate aspect of our results is that total surplus comes out to be negative. This result is driven by the fact that our model is predicting very elastic demand and by the fact that the data shows that the number of admissions per hospital is significantly smaller than the total market size as determined by our $\theta$ parameters, which implies that hospitals must not be of very high quality relative to the outside alternative. However, we note that the firm-level results all replicate

15. Table III also shows the results of the model for two other cases: first, allowing only NPs to enter, and second, allowing only FPs to enter. These are discussed in Section 4.2 . 
TABLE III.

LONG-RUN INDUSTRY CHARACTERISTICS: BASE CASE, Allowing ONLy NONPROFits, AND Allowing ONLY FOR-PROFITS

\begin{tabular}{|c|c|c|c|c|c|c|}
\hline \multirow[b]{2}{*}{ Quantity } & \multicolumn{6}{|c|}{ Value } \\
\hline & \multicolumn{2}{|c|}{ Base Case } & \multicolumn{2}{|c|}{ Only NP } & \multicolumn{2}{|c|}{ Only FP } \\
\hline \multicolumn{7}{|c|}{ Consumer and Welfare Statistics } \\
\hline Mean total surplus (M\$) & \multicolumn{2}{|c|}{-5.0} & \multicolumn{2}{|c|}{-4.2} & & -12.6 \\
\hline Mean producer surplus (M\$) & \multicolumn{2}{|c|}{-4.3} & \multicolumn{2}{|c|}{-4.6} & & -3.7 \\
\hline Mean consumer surplus (M\$) & \multicolumn{2}{|c|}{47.5} & \multicolumn{2}{|c|}{49.4} & & 30.6 \\
\hline Sales-weighted list price (\$) & \multicolumn{2}{|c|}{5809} & \multicolumn{2}{|c|}{5818} & & 5623 \\
\hline $\begin{array}{l}\text { Insured-patient consumer } \\
\text { surplus (M\$) }\end{array}$ & \multicolumn{2}{|c|}{19.3} & \multicolumn{2}{|c|}{20.4} & & 20.0 \\
\hline $\begin{array}{l}\text { Uninsured-patient consumer } \\
\text { surplus }(\mathrm{k} \$)\end{array}$ & \multicolumn{2}{|c|}{327} & \multicolumn{2}{|c|}{337} & \multicolumn{2}{|r|}{231.3} \\
\hline $\begin{array}{l}\text { Medicare/Medicaid consumer } \\
\text { surplus (M\$) }\end{array}$ & \multicolumn{2}{|c|}{27.9} & \multicolumn{2}{|c|}{28.7} & \multicolumn{2}{|r|}{10.3} \\
\hline Patients receiving free care $(\%)$ & \multicolumn{2}{|c|}{15.0} & \multicolumn{2}{|c|}{14.8} & \multicolumn{2}{|r|}{17.5} \\
\hline \multicolumn{7}{|c|}{ Government Revenues and Expenditures } \\
\hline $\begin{array}{l}\text { Income- and property-tax } \\
\text { revenue }(\mathrm{k} \$)\end{array}$ & \multicolumn{2}{|c|}{1.7} & \multicolumn{2}{|c|}{0} & \multicolumn{2}{|r|}{20} \\
\hline Medicare/Medicaid & \multicolumn{2}{|c|}{48.3} & \multicolumn{2}{|c|}{49.0} & \multicolumn{2}{|r|}{39.4} \\
\hline & \multicolumn{4}{|c|}{ Firm Characteristics } & & \\
\hline & $\mathrm{Ba}$ & ase & Only & & & ly FP \\
\hline & NP & FP & NP & $\mathrm{FP}$ & NP & $\mathrm{FP}$ \\
\hline Average profits $(\mathrm{k} \$)$ & -800 & -89 & -800 & $\mathrm{n} / \mathrm{a}$ & $\mathrm{n} / \mathrm{a}$ & -91 \\
\hline Average price/cost margin & 1.00 & 1.02 & 1.00 & $\mathrm{n} / \mathrm{a}$ & $\mathrm{n} / \mathrm{a}$ & 1.02 \\
\hline Average quality & 1.79 & 1.09 & 1.79 & $\mathrm{n} / \mathrm{a}$ & $\mathrm{n} / \mathrm{a}$ & 1.01 \\
\hline Average investment $(\mathrm{k} \$)$ & 600 & 1200 & 1200 & $\mathrm{n} / \mathrm{a}$ & $\mathrm{n} / \mathrm{a}$ & 632 \\
\hline Average lifespan (yr) & 94 & 20 & 95 & $\mathrm{n} / \mathrm{a}$ & $\mathrm{n} / \mathrm{a}$ & 20 \\
\hline Periods with exit/entry (\%) & 3.6 & 2.4 & 4.1 & $\mathrm{n} / \mathrm{a}$ & $\mathrm{n} / \mathrm{a}$ & 17 \\
\hline Average no. of hospitals & & & & & & 3.15 \\
\hline Average NPs/FPs (\%) & & & & & & 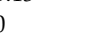 \\
\hline
\end{tabular}

well-known facts about the hospital industry that we did not attempt to match in our estimation process. For instance, NP firms live longer than FPs, they are of higher quality on average, ${ }^{16}$ and FPs have, on average, higher price/cost margins than NPs. ${ }^{17}$ This is interesting because statically both NPs and FPs are profit maximizers. It is their 
different dynamic behaviors that lead to the different behaviors that one can find in the data. ${ }^{18}$

\subsection{THE ROLES SERVED BY NPS AND FPS IN OUR MODEL}

To illustrate the roles that NP and FP hospitals serve in our model, we compare our base-case results with two separate models, where we allow only NPs and only FPs respectively. ${ }^{19}$ Table III details the differences between the three models. We can see that patients of all types fare best when only NP hospitals are allowed and worst when only FP hospitals are allowed. The reason for this is twofold: first, FPs will be of lower quality, and second, there are more hospitals available to choose from when NPs are allowed, and this increased competition results in hospitals charging a lower price for a given quality level. Interestingly enough, although NP hospitals have generally been linked to uninsured benefits, ${ }^{20}$ it is the Medicare and Medicaid patients who benefit the most from having only NP hospitals present, because of the increase in quality that results from this policy. There is one clear winner in the case of only FPs, and it is the government. Both local and the Federal government collect no tax revenue if FPs are not allowed, some tax revenue if both types of firms are allowed, and many times as much tax revenue if no NPs are allowed. However, in this case, the increase in government revenue does not compensate for the lost consumer surplus. Finally, we note that industry performance is quite different when either NPs or FPs are not allowed; the distribution of firm structures for NP and FP firms, in terms of investment levels, price/cost margins, lifespans and profits, remains relatively constant between these cases.

This experiment suggests a very simple justification for the existence of NPs. Weisbrod (1975) has suggested that NPs exist to provide a public good that is insufficiently provided by the market or the government. Hansmann (1980) has argued that NPs exist to solve an infor-

18. Current antitrust policy does not differentiate between NPs and FPs when analyzing the competitive effects of hospital mergers. Our work suggests that the ultimate competitive effect may depend on the profit status of the hospital. While static models such as Dor and Rizzo (1993) have analyzed the different implications of mergers for NPs and FPs, our model suggests the need for a dynamic examination of this behavior.

19. Recall that in the base case, at every period, two potential entrants, one NP and one $\mathrm{FP}$, each receive independent draws on entry cost from some distribution. In order to treat symmetrically the cases where one type of ownership is prohibited, we give two independent entry draws to the potential entrant of the allowed type, for these cases. The entrant will then choose the lower of these two draws.

20. See, for instance, Frank and Salkever (1991). 
mation problem. In our model, neither view is correct. NPs exist simply because they get utility from providing a service. Furthermore, consumers benefit from NPs simply because their existence increases competition and choice.

\section{POLICY EXPERIMENTS}

In this section, we perform three policy experiments: changing the Medicare system from retrospective payment to prospective payment, providing universal health insurance, and removing NP hospitals' taxexempt status. Our point of reference for each experiment will be the 1991 base-case results, which we discussed in Section 4.

\subsection{The Retrospective Payment System}

Prior to 1984, the Medicare system reimbursed hospitals under the retrospective payment system (RPS). RPS reimbursed hospitals for their treatment of Medicare patients on an individual-hospital historical-cost basis. In an effort to reduce the growth rate of Medicare expenditures, Congress instituted a prospective payment system which paid hospitals a fixed rate for each patient based upon her diagnosis. In addition, the average margin hospitals earn for treating Medicare patients has been declining steadily since $1986 .{ }^{21}$

There are several questions we have in mind as we perform the RPS experiment. What effect did the shift in payment systems have upon market structure? Which had a greater effect on market structure: fixing the payments or lowering the Medicare margins? What is the effect on welfare of changing the payment system? Lastly, who are the potential winners and losers under the new system? These are the type of questions that only a fully dynamic model can hope to answer.

In order to implement the RPS experiment, we change the Medicare reimbursement rate in the base case, from a constant per patient (as under the PPS), to be equal to 1.1 times the hospital's marginal cost for that patient. In order to isolate the effects of the increase in Medicare payments from the effects of cost-based reimbursement, we also calculated the model with the PPS payment equal to $120 \%$ of the 1991 levels, as this level results in the same level of government Medicare expenditures as the RPS experiment.

21. See Prospective Payment Assessment Commission (1992) for details. Margin here refers to the difference between average revenue and average (as opposed to marginal) cost. 
TABLE IV.

LONG-RUN INDUSTRY CHARACTERISTICS: RPS EXPERIMENT

\begin{tabular}{|c|c|c|c|c|c|c|}
\hline \multirow[b]{3}{*}{ Quantity } & \multicolumn{6}{|c|}{ Valve } \\
\hline & \multicolumn{2}{|c|}{ Base case } & \multicolumn{4}{|c|}{ Experiment } \\
\hline & \multicolumn{2}{|c|}{ PPS } & \multicolumn{2}{|c|}{$\begin{array}{c}\text { PPS: } 120 \% \\
\text { Reimbursement }\end{array}$} & \multicolumn{2}{|c|}{ RPS } \\
\hline \multicolumn{7}{|c|}{ Consumer and Welfare Statistics } \\
\hline $\begin{array}{l}\text { Mean total surplus }(\mathrm{M} \$) \\
\text { Mean producer surplus }(\mathrm{M} \$) \\
\text { Mean consumer surplus }(\mathrm{M} \$) \\
\text { Sales-weighted list price }(\$)\end{array}$ & & & 58 & $\begin{array}{l}56 \\
2 \\
4\end{array}$ & & $\begin{array}{l}50 \\
.5 \\
3\end{array}$ \\
\hline $\begin{array}{l}\text { Insured-patient consumer } \\
\text { surplus (M\$) }\end{array}$ & \multicolumn{2}{|c|}{19.3} & \multicolumn{2}{|c|}{23.3} & \multicolumn{2}{|c|}{23.3} \\
\hline $\begin{array}{l}\text { Uninsured-patient consumer } \\
\text { surplus (k\$) }\end{array}$ & \multicolumn{2}{|c|}{327} & \multicolumn{2}{|c|}{366} & \multicolumn{2}{|c|}{366} \\
\hline $\begin{array}{l}\text { Medicare/Medicaid consumer } \\
\text { surplus (M\$) }\end{array}$ & \multicolumn{2}{|c|}{27.9} & \multicolumn{2}{|c|}{30.8} & \multicolumn{2}{|c|}{30.8} \\
\hline Patients receiving free care $(\%)$ & \multicolumn{2}{|c|}{15.0} & \multicolumn{2}{|c|}{14.3} & \multicolumn{2}{|c|}{14.3} \\
\hline \multicolumn{7}{|c|}{ Government Revenues and Expenditures } \\
\hline $\begin{array}{l}\text { Income- and property-tax } \\
\text { revenue (\$) }\end{array}$ & \multicolumn{2}{|c|}{1700} & & & & \\
\hline Medicare/Medicaid & & & & & & 6 \\
\hline & Firm & zaracterist & & & & \\
\hline & Bas & ase & & Expe & ment & \\
\hline & & & $\begin{array}{l}\text { PPS: } \\
\text { Reimbu }\end{array}$ & $\begin{array}{l}0 \% \\
\text { ement }\end{array}$ & & \\
\hline & NP & FP & NP & FP & NP & FP \\
\hline Average profits $(\mathrm{k} \$)$ & -800 & -89 & 1400 & 665 & 1000 & 466 \\
\hline Average price/cost margin & 1.00 & 1.02 & 1.08 & 1.09 & 1.07 & 1.06 \\
\hline Average quality & 1.79 & 1.09 & 2.05 & 1.81 & 2.05 & 1.80 \\
\hline Average investment (M\$) & 0.6 & 1.2 & 1.5 & 1.6 & 1.5 & 1.5 \\
\hline Average lifespan (yr) & 94 & 20 & 439 & 81 & 389 & 68 \\
\hline Periods with exit/entry (\%) & 3.6 & 2.4 & 1.6 & 0.01 & 2 & 0.2 \\
\hline Average no. of hospitals & & 30 & & & & \\
\hline Average NPs/FPs (\%) & & & & & & \\
\hline
\end{tabular}

Table IV describes the characteristics of the ergodic distribution under RPS relative to the PPS with both levels of payment. We find that the drop in reimbursement levels had a larger effect than the change to PPS. Additionally, the change in policy ultimately led to a decline in total welfare even though government expenditures are significantly 
lower than under the old payment system. There are two reasons for this. First, under the PPS, hospitals have a lower average quality, which leads to lower consumer surplus for all patients; this drop in quality is an unintended effect of the policy shift. Second, hospital profits are lower under the PPS. While we are hesitant to take these results and argue that this shift in policy led to a real-world reduction in welfare, we think this finding is illustrative of the usefulness of a dynamic model in highlighting the unintended effects of policy changes.

Table IV also shows that lower reimbursement rates lead to cost shifting, as non-Medicare patients pay almost as much for lower-quality care: the shift in payment mechanism ultimately leads to a $10 \%$ reduction in the average quality of hospitals, while average price declines by less than $1 \%$. This occurs because the less generous payment system leads to more concentrated markets, and hospitals, on average, have more market power. Previous theoretical studies have either postulated that prices for privately insured patients would fall in response to a fall in Medicare payments ${ }^{22}$ or that any cost shifting is evidence that hospitals choose quantity maximizing behavior. ${ }^{23}$ Our result is interesting, because while cost-shifting has been empirically observed ${ }^{24}$ our explanation is the first model that incorporates profitmaximizing behavior; in static models, given profit maximization, changes in Medicare reimbursement rates will not affect privately insured prices since the former are essentially fixed costs.

\subsection{UNIVERSAL HEALTH INSURANCE}

We perform two variants of a policy experiment that is designed to resemble one of the health reform ideas proposed by the Clinton administration under the proposed Health Reform Act of 1994. In both experiments the federal government provides health insurance for the currently uninsured population. We assume that the currently uninsured enroll in the same insurance program as the privately insured population and the government pays the insurance premiums. In the first experiment, we assume that the government finances this program with some unspecified income-tax increase. In the second case, we assume that the government finances the program by implementing a $5 \%$ revenue tax on hospitals. We choose the tax rate so that the increase in expenditures necessitated by the insurance program would roughly

23. See Dranove (1988).

24. Dranove (1988), for instance, finds cost-shifting behavior using Illinois data. 
TABLE V.

LONG-RUN INDUSTRY CHARACTERISTICS: EXPERIMENT WITH UNIVERSAL HEALTH-CARE COVERAGE

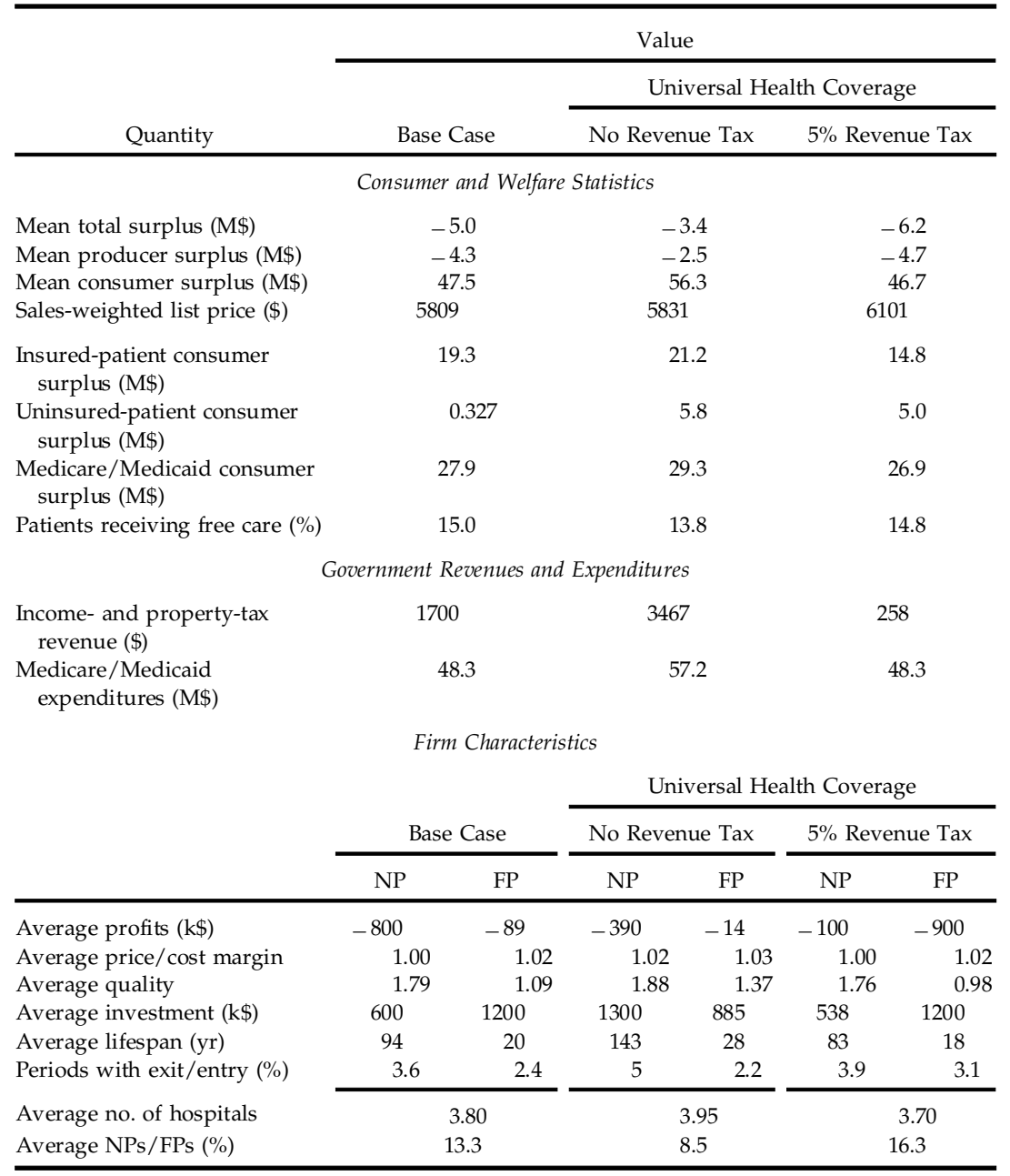

balance the extra revenues generated by the tax. We do not model here the effects of the change in incentives to purchase health insurance that such a program would cause.

The results of these experiments are summarized in Table V. First we examine the proposal financed with the income tax. In this experiment, not only does the uninsured population experience a large in- 
crease in welfare, but all types of patients benefit from the provision of insurance to the previously uninsured through increased hospital competition. The additional insurance increases the demand for hospital services, which increases the profitability of operating a hospital. These profits attract entry, increasing competition and increasing average quality in the industry. In spite of the increase in welfare to uninsured patients from the new plan, the program does not result in a large decrease in the amount of free care provided by hospitals. The reason for this is that there is still a copayment requirement. The program costs the government about $\$ 9$ million per period. That is, in order to finance the program the government would have to increase the per capita tax burden by $\$ 36$. Note that this tax burden is less than the added benefit from the new insurance program, and thus total welfare is increased by this policy.

Table $\mathrm{V}$ also presents the results of the universal health insurance program under the alternative financing scheme. Here we impose a $5 \%$ tax on hospital revenues. With this tax, the government is able to fully finance the program. Not surprisingly, the welfare of the uninsured patients increases with this policy. However, the overall welfare declines significantly relative to the base-case experiment. That is, the privately insured populations experience a large decline in their welfare. The reason for this is straightforward. The tax causes hospitals to exit the industry, concentration increases, and the amount of market power hospitals are able to exercise increases. Furthermore, the population is more price-insensitive. The net effect is that hospital prices increase by $5 \%$ even though average hospital quality decreases. While the effects on a city of 250,000 are significant, a smaller city would experience an even larger decrease in welfare.

We believe that the message from this experiment is quite clear. Government intervention can result in better, more cost-effective hospital care. However, a poorly conceived intervention can ultimately foul the workings of the hospital market, leaving patients with lower-quality hospital services for a higher price.

\subsection{TAXING NONPROFIT HOSPITALS}

Some legislators have discussed the possibility of revoking the taxexempt status of NP hospitals. In general, most of these proposals have been made because there has been rising concern that NP hospitals are not providing enough care to the indigent population. In this experiment we want to see what the effect of taxing NPs would be on overall welfare. In addition, this experiment should render some insights into the role that NPs play in the provision of hospital care. 
TABLE VI.

LONG-RUN INDUSTRY CHARACTERISTICS: EXPERIMENT WITH TAXING NONPROFIT HOSPITALS

\begin{tabular}{|c|c|c|c|c|}
\hline \multirow[b]{2}{*}{ Quantity } & \multicolumn{4}{|c|}{ Value } \\
\hline & \multicolumn{2}{|c|}{ Base Case } & \multicolumn{2}{|c|}{$\begin{array}{c}\text { Taxing Nonprofit } \\
\text { Hospitals }\end{array}$} \\
\hline \multicolumn{5}{|c|}{ Consumer and Welfare Statistics } \\
\hline $\begin{array}{l}\text { Mean total surplus }(\mathrm{M} \$) \\
\text { Mean producer surplus (M\$) } \\
\text { Mean consumer surplus (M\$) } \\
\text { Sales-weighted list price (\$) }\end{array}$ & & & & \\
\hline $\begin{array}{l}\text { Insured-patient consumer } \\
\text { surplus (M\$) }\end{array}$ & \multicolumn{2}{|c|}{19.3} & \multicolumn{2}{|c|}{18.8} \\
\hline $\begin{array}{l}\text { Uninsured-patient consumer } \\
\text { surplus }(\mathrm{k} \$)\end{array}$ & \multicolumn{2}{|c|}{327} & \multicolumn{2}{|c|}{322} \\
\hline $\begin{array}{l}\text { Medicare/Medicaid consumer } \\
\text { surplus (M\$) }\end{array}$ & \multicolumn{2}{|c|}{27.9} & \multicolumn{2}{|c|}{27.6} \\
\hline Patients receiving free care $(\%)$ & \multicolumn{2}{|c|}{15.0} & \multicolumn{2}{|c|}{15.0} \\
\hline \multicolumn{5}{|c|}{ Government Revenues and Expenditures } \\
\hline $\begin{array}{l}\text { Income- and property-tax } \\
\text { revenue }(\$)\end{array}$ & \multicolumn{2}{|c|}{1700} & \multicolumn{2}{|c|}{4835} \\
\hline $\begin{array}{l}\text { Medicare /Medicaid expenditures } \\
\text { (M\$) }\end{array}$ & \multicolumn{2}{|c|}{48.3} & \multicolumn{2}{|c|}{48.0} \\
\hline \multicolumn{5}{|c|}{ Firm Characteristics } \\
\hline & \multicolumn{2}{|c|}{ Base Case } & \multicolumn{2}{|c|}{$\begin{array}{c}\text { Taxing Nonprofit } \\
\text { Hospitals }\end{array}$} \\
\hline & NP & FP & NP & FP \\
\hline Average profits $(\mathrm{k} \$)$ & 800 & -89 & -490 & -88 \\
\hline Average price/cost margin & 1.00 & 1.02 & 1.00 & 1.02 \\
\hline Average quality & 1.79 & 1.09 & 1.93 & 1.09 \\
\hline Average investment $(\mathrm{k} \$)$ & 600 & 1200 & 889 & 614 \\
\hline Average lifespan (yr) & 94 & 20 & 37 & 20 \\
\hline Periods with exit/entry (\%) & 3.6 & 2.4 & 8.1 & 3.8 \\
\hline Average no. of hospitals & \multicolumn{2}{|c|}{3.80} & \multicolumn{2}{|c|}{3.66} \\
\hline Average NPs/FPs (\%) & \multicolumn{2}{|c|}{13.3} & \multicolumn{2}{|c|}{24.8} \\
\hline
\end{tabular}

In this experiment, we levy the same income and property taxes upon NPs that FP hospitals have to pay (Table VI). Putting NP hospitals on the same competitive footing as FPs reduces the number of NPs relative to FPs and increases market concentration. Total welfare increases slightly, although consumer welfare declines as the number of 
hospitals they have to choose from decreases and the price they pay for treatment increases slightly, this decline in consumer surplus is more than offset by the increase in total producer surplus. This increase is the result of lessening the incentive to overinvest in quality by reducing the viability of the higher-quality NPs. Not surprisingly, one loser is NP hospitals, which see their average profits decline. While this policy has a significant effect on the firms and consumers, the net effects appear to be only slightly beneficial, and almost balance out. Again, these are the type of results that can only be predicted by a dynamic model.

\section{CONCLUSION}

In this paper, we have presented a dynamic model of hospital equilibrium with entry, exit, and investment and have econometrically estimated this model to fit empirically observed data. Since there have not been any previous dynamic models of the hospital industry of this kind, our model represents a first attempt at structurally modeling and estimating the industry. Although we have simplified the industry to consider hospital care as a single product, to allow patients the choice of all hospitals in their area, and to look at indemnity insurance only, our model still generates predictions that are close to reality. Additionally, our model also points out the advantages and disadvantages of a hospital system where both NP and FP firms coexist, and shows that allowing NPs to operate in this industry may be optimal. We then apply the model to various policy experiments and show that these may sometimes have unexpected consequences. In particular, we find that the largest effect of the change in the Medicare reimbursement system was that non-Medicare patients lost from poorer treatment at a higher price. Although this cost-shifting behavior has been widely observed in the data, ours is the first model that can explain this pattern of change in a rational profit-maximizing setting. In addition, we find that a plan to insure all uninsured patients can be beneficial or harmful, depending on the source of funding for this plan. Finally, our model shows that taxing NP hospitals may be slightly beneficial, as it would lessen the incentives of these hospitals to provide care of higher quality than is socially optimal.

The hospital industry is directly and indirectly influenced by government policies, from tax exemptions to employer mandates to Medicare payments. The model shows that these policies will have important effects on the quality, availability, and price of future hospital services, and that these changes are manifested largely through the dynamic 
determinants of firm behavior. While other economists have certainly been aware that the change in industry structure and welfare is due largely to the dynamic effects that policy changes have, our paper attempts to quantify exactly what these dynamic effects are. Thus, by estimating a dynamic structural model of equilibrium in the hospital industry, our paper is able to separate the different opposing effects of policy changes in order to determine their relative magnitudes, and predict which effects will dominate. Accordingly, a dynamic model such as ours is necessary to unravel the effects of government policies that were considered in the past, such as plans for universal health-care coverage, those being considered today, such as changing Medicare deductibles, and those that will be considered in the future.

As our model is the first to attempt to predict hospital behavior, it is not the last word on modeling the hospital industry dynamically. We stress that the results presented here are from preliminary estimates of the parameters and there are many potential improvements to the model and estimation process which will alter its predictions. Potential improvements to the model include: allowing hospitals to change ownership status for a fee, allowing patients to endogenously choose whether or not to purchase insurance, allowing different patients to have different severities of illness, allowing for hospital mergers, modeling price regulation, allowing hospitals to choose the length of stay or intensity of their treatment, and allowing hospitals to screen uninsured patients. Potential improvements to the estimation process include: better data on revenues and probabilities of illness, region-specific data instead of aggregate national data, data on entry and exit behavior, and an estimation process that does not make the assumption that the industry is in long-run equilibrium. All of these improvements will lead us further towards our ultimate goal in this research, which is to more precisely characterize the hospital industry.

\section{REFERENCES}

Caplin, A. and B. Nalebuff, 1991, "Aggregation and Imperfect Competition: On the Existence of Equilibrium," Econometrica, 59, 25-59.

Current Population Survey: March, 1991, Washington, DC: Bureau of the Census.

Dor, A. and J. Rizzo, 1993, "The Welfare Effects of Mergers in a Regulated Service Industry," Mimeo, Yale University.

Dranove, D., 1988, "Pricing by Non-profit Institutions: The Case of Hospital Cost-Shifting," Journal of Health Economics, 7, 47-57.

Ericson, R. and A. Pakes, 1995, "An Alternative Theory of Firm and Industry Dynamics," Review of Economic Studies, 62, 53-82.

Foster, R., 1985, "Cost-Shifting under Cost Reimbursement and Prospective Payment," Journal of Health Economics, 4, 261-271. 
Frank, R. and D. Salkever, 1991, "The Supply of Charity Services by Non-profit Hospitals: Motives and Market Structure," RAND Journal of Economics, 22, 430-445.

Gowrisankaran, G. and R. Town, 1995, "Dynamic Equilibrium in the Hospital Industry," Mimeo, U.S. Department of Justice.

Gray, B., 1991, The Profit Motive and Patient Care: The Changing Accountability of Doctors and Hospitals, Cambridge, MA: Harvard University Press.

Hansen, L., 1982, "The Large Sample Properties of Generalized Method of Moments Estimators," Econometrica, 50, 1029-1054.

Hansmann, H., 1980, "The Role of Non-profit Enterprise," Yale Law Journal, 89, 835-901. Hay, J., 1983, "The Impact of Public Health Care Financing Policies on Private Sector Hospital Costs," Journal of Health Politics, Policy and Law, 7, 945-952.

Health Care Financing Administration, 1993, Health Care Financing Review, Washington, DC.

Hoerger, T., 1991, "“Profit' Variability in For-Profit and Not-for-Profit Hospitals," Journal of Health Economics, 10, 259-289.

Holmes, T. and J. Schmitz, 1995, “On the Turnover of Business Firms and Business Managers," Journal of Political Economy, 103, 1005-1038.

Manning, W., J. Newhouse, N. Duan, E. Keeler, A. Leibowitz, and M. Marquis, 1987, "Health Insurance and the Demand for Medical Care: Evidence from a Randomized Experiment," American Economic Review, 77, 251-277.

Maskin, E. and J. Tirole, 1988a, "A Theory of Dynamic Oligopoly I: Overview and Quantity Competition with Large Fixed Costs," Econometrica, 56, 549-569.

—_ and _ - 1988b, "A Theory of Dynamic Oligopoly II: Price Competition, Kinked Demand Curves, and Edgeworth Cycles," Econometrica, 56, 571-599.

McFadden, D., 1981, "Econometric Models of Probabilistic Choice," in C. Manski and D. McFadden, eds., Structural Analysis of Discrete Data with Econometric Applications, Cambridge: MIT Press, 198-269.

Newhouse, J., 1970, "Towards a Theory of Non-Profit Institutions: An Economic Model of a Hospital," American Economics Review, 60, 87-92.

Pakes, A., 1986, "Patents as Options: Some Estimates of the Value of Holding European Patents," Econometrica, 54, 1986, 755-784.

-_ and P. McGuire, 1994, "Computing Markov Perfect Nash Equilibria: Numerical Implications of a Dynamic Differentiated Product Model," RAND Journal of Economics, $25,555-589$.

-_, G. Gowrisankaran, and P. McGuire, 1993, "Implementing the Pakes-McGuire Algorithm for Computing Markov Perfect Equilibria in Gauss," Mimeo, Yale University.

Patel, J., J. Needleman, and R. Zeckhauser, 1993, “Changing Fortunes: Hospital Behavior by Ownership Form," Mimeo, Kennedy School of Government, Harvard University.

Prospective Payment Assessment Commission, 1992, Medicare and the American Health Care System: Report to Congress, Washington, DC.

Wedig, G., M. Hassan, and F. Sloan, 1989, "Hospital Investment Decisions and the Cost of Capital," Journal of Business, 62, 517-537.

Weisbrod, B., 1975, "Toward a Theory of the Voluntary Non-profit Sector in a ThreeSector Economy," in Edmond Phillips, ed., Altruism, Morality, and Economic Theory, New York: Russell Sage Foundation. 
Copyright of Journal of Economics \& Management Strategy is the property of MIT Press and its content may not be copied or emailed to multiple sites or posted to a listserv without the copyright holder's express written permission. However, users may print, download, or email articles for individual use. 